\title{
Institutional reforms and agricultural policy process: lessons from Democratic Republic of Congo
}

\author{
Catherine Ragasa ${ }^{1 *+}$, Suresh C Babu ${ }^{2+}$ and John Ulimwengu ${ }^{3+}$
}

\author{
* Correspondence: c.ragasa@cgiar.org \\ ${ }^{\dagger}$ Equal contributors \\ ${ }^{1}$ Development Strategy and \\ Governance Division, International \\ Food Policy Research Institute (IFPRI), \\ 2033 K Street, NW, Washington DC \\ 20006, USA \\ Full list of author information is \\ available at the end of the article
}

\begin{abstract}
Attaining food security for all requires well-functioning institutions and policy process that are effective in designing and implementing food and agricultural policies and programs. This paper assesses early stages of the decentralization and institutional reforms in the policymaking processes in the Democratic Republic of Congo (DRC). It develops a conceptual framework and adopts an innovative mapping tool to identify capacity and incentive challenges impeding the effective design and implementation of food and agricultural policy and institutional reform processes. We found that decentralized platforms for policy dialogues have the potential to improve civil society participation in local-level and national-level policy and planning processes. However, their success depends on organizational and human capacity strengthening, financial sustainability, effective participation of the civil society, and demonstrated impact of their participation.
\end{abstract}

JEL Classification: D72; D74; D78; Q18

Keywords: Food security; Institutional reforms; Policy process; Decentralization; Network mapping; Capacity development; Post-conflict; Agriculture

\section{Background}

Attaining food security for all in countries that are behind in achieving Millennium Development Goals requires institutional and policy reforms that will help the food and agricultural system to become more productive and efficient in the use of natural resources. The role of institutions, governance, and the capacity of countries in efficient use of development assistance remain on the top of the research agenda of the development community (Killick 2010). However, how such research can result in better development practice such as removal of barriers to development investments is still to be seen (Booth 2011). Institutional reforms and innovations require recognition of the nature and state of organizational and human capacity ${ }^{\mathrm{a}}$ in the country context and how such capacity can be further developed to achieve clear development goals (Grindle 2007). The challenge for the development organizations is to understand the process of institutional reform in order to facilitate positive changes in the specific practical, economic, and organizational contexts. Learning from the institutional reform experiences and the policy processes ${ }^{\mathrm{b}}$ is vital for increasing effectiveness of development assistance. In this paper we use the case of Democratic Republic of Congo 
(DRC) and focus on its policymaking and capacity development processes to derive specific lessons for the countries facing challenges in achieving food security for all.

In post-conflict societies, such as DRC, opportunities arise for reforms in policies and institutions. Yet, serious capacity gaps ${ }^{\mathrm{c}}$ often constrain the effective design and implementation of institutional reforms. DRC, after episodes of war that devastated much of its human capital and physical infrastructure, provides a good setting to analyze the opportunities for policy and institutional reforms as well as sequencing and complementing these reform processes with capacity development approaches. DRC is considered as a key agricultural producer in Africa before the war; and estimates suggest that if agricultural productivity were to catch up with the global technological frontier, DRC could feed around one-third of the world's population (Tollens 2004). It is endowed with 80 million hectares of arable land (of which 4 million are irrigable), 125 million of tropical forest representing 6 percent of world forest reserves, climatic diversity allowing multiple agricultural seasons in the same year, grazing land capable of supporting nearly 40 million head of cattle, inland fisheries resources that can enable annual production of at least 700,000 tons of fish, and rich ecology and abundant hydrology that can allow the practice of various farming activities (World Bank 2006).

In an effort to increase economic development by rebuilding its agriculture and economic sectors, DRC is embarking on several institutional reform processes, including more demand-driven, inclusive, and evidence-based policymaking and planning. In the agricultural sector, the country has set up Agricultural and Rural Management Councils (CARGs), which are a platform for discussion, information sharing, and formulation of local agricultural strategies, in its territories and provinces. Additionally, DRC is restructuring and decentralizing its Ministry of Agriculture, Fisheries, and Livestock (MINAGRI) and Ministry of Rural Development (MINRD) to make them efficient and responsive to the needs of the population. In June 2010, DRC committed to increase its agricultural GDP and its budget share for agriculture through the launch of the Comprehensive Africa Agricultural Development Programme (CAADP) framework. A number of international organizations have supported the agricultural sector through numerous projects and programs that provide basic and economic services directly to beneficiaries to help them increase their income. However, none of them has looked at the broader organizational capacity constraints involved in policymaking and planning. For increasing the effectiveness of aid, it is important to identify such organizational and capacity constraints and to understand how donor support could "build on" what is already there, in order to remove disincentives and blockages in the process of evidence-based policy making (Grindle 2007). An innovative methodology is used to study the policy process in the DRC agricultural sector in the context of the processed institutional reforms and organizational and capacity constraints.

This paper provides two unique contributions to the literature. First, it offers a conceptual framework of analyzing the nexus of incentives and capacity in institutional and policy reform processes. While the incentives and civil-service reforms have been recognized in the literature, they have rarely been included or paid attention to in training needs assessment or capacity assessment and subsequent training and capacity development activities. Second, this paper applies a simple, yet powerful, tool for rapid assessment to identify key actors, their linkages, constraints, capacity, and incentives. In addition, this paper aims to inform policymakers, stakeholders, and international 
partners on the constraints and feasible options available to more fully develop agricultural sector.

The paper is organized as follows. A conceptual framework is developed in the next section after a brief review of institutional reform and policy process literature. In section three, we present the methods used. In section four, we apply the framework and methods to study the recent institutional reform processes in the food and agricultural sector of DRC. Section 5 draws specific lessons and implications from the case study. conclusion forms the last section.

\section{Literature review and a conceptual framework}

Two strands of literature guide the process of developing a conceptual framework to study institutional reforms in the context of capacity constraints. First, the policyprocesse literature helps to identify the institutional reforms that needed for evidencebased policymaking in developing countries; and second, the organizational and capacity development literature helps to understand various factors affecting the organizational performance of institutional reform process. In addition, recent scholarship places high emphasis on understanding institutional and policy responses during emerging challenges such as food crisis and resilience of developing countries to face such crisis (Babu 2013).

While several theories exist, empirical investigation of policy process in the context of developing countries is scarce (Court and Young 2003; Omamo 2004; Sabatier 2007; Resnick and Birner 2010). Research-policy linkages, a subset of the policy process literature, have received some attention (see Ryan 1999; Guston 2001; Stone et al. 2001; Court and Young 2003; Cash et al. 2003; Young 2005; Ayuk and Marouani 2007; and Aberman et al. 2010). Ayuk and Marouani (2007) assess multiple case studies of policy-research links and highlight the nonlinear nature of the link between research and policy, which requires flexibility and agility on the part of researchers to seize opportunities and to quickly reassess and recalibrate research approaches as needed. Aberman et al. (2010) find that champions of research within policymaking circles are key to the application of research to policy, and that strong ties between researchers and technocrats likewise played an essential role in ensuring government buy-in. Despite this body of literature on policy processes and research, obvious gaps remain.

Capacity development process and policy process are widely discussed in the literature as two separate disciplines; they are rarely analyzed systematically together. For example, on one hand, a major stumbling block for decentralization and privatization policies in extension services delivery is the lack of proper capacity assessment and subsequent investments in capacity development; while major constraints in pluralistic and demand-driven service delivery systems are the lack of capacity for administration and management of funds as well as a shortage of service providers (see Rivera and Alex 2004; World Bank 2010). On the other hand, training and capacity development efforts are not effective and will not lead to desirable impacts without enabling policy environment, and institutional and organizational reforms (Adebayo et al. 2009; Babu et al. 2007), and civil service reforms (World Bank 1999). How these two processes are interlinked, how to design and implement interventions that contribute to the two processes, and how they are effectively sequenced remain a major research gap.

Given this backdrop, this paper addresses the current research gap in understanding the role of institutional reforms in the evidence-based policy process. It develops a 
framework and applies an expanded mapping tool that incorporates elements of capacity and incentive conditions surrounding policy processes.

The framework centers on a clearly defined development goal (or outcome) of interest that the country or sector is aiming to achieve (Figure 1). Agricultural development can be achieved by aspiring for efficiency, effectiveness, and sustainability of organizations that are effective in key processes in the agricultural sector management, namely: (1) inclusive and evidence-based policymaking and planning, (2) adequate and predictable resources, (3) effective and demand-driven service provision, and (4) enforceable regulations. Outcomes of these processes will have to be combined to produce development impacts. These collective functions of agricultural-sector management have to be guided by the strategic direction and measurable performance targets broadly shared among the actors and organizations.

The organizational performance and effectiveness of key processes are in turn conditioned by incentive and capacity, which are influenced by the organizational or institutional landscape, country context, and broader enabling environment. Organizational capacity is characterized by management systems and procedures for coordination and communication, and availability and adequacy of financial and physical resources. Human capacity, which reflects the quantity and quality of human resources and social capital, is the summation of skills, knowledge, and competencies of individuals. It is also a crucial factor in achieving pre-defined objectives and development goals. Education and training systems of a country play a critical role in capacity development; while well-designed external support to the education system or directly to the organizations is potentially important in moving out of path dependency and embracing reforms and change.

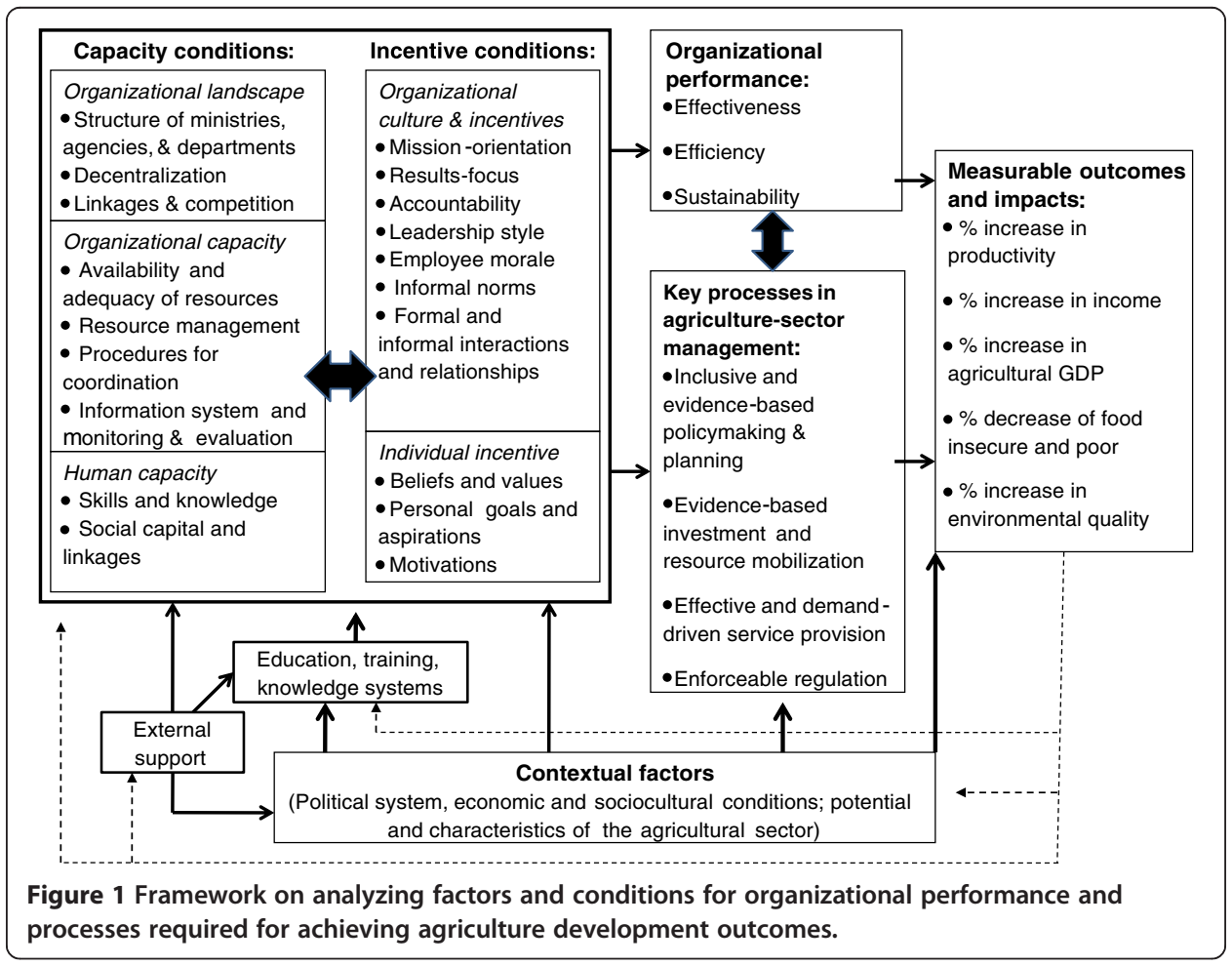


Incentives are inherent to individuals' preferences and needs and influenced by the nature of both formal and informal institutions or norms at different levels (country, sector, organization, or unit level) and can be manifested in the degree of external checks and balances and organizational culture. External checks and balances in the form of client feedback and other related external pressures are likely to elicit demandside accountability and are capable of influencing behavior if grounded with a credible incentive system to perform. Incentives can be in the form of monetary or nonmonetary benefits of a particular decision or action. Organizational culture, which represents "the collection of traditions, values, policies, beliefs and attitudes that constitute a pervasive context for everything we do and think in an organization" is an important factor that may affect incentives of individuals to perform (Marshall and McLean 1988, page 32).

In the next sections we apply this conceptual framework to study the organizational and human capacity constraints and challenges as they relate to the institutional reforms undertaken in the DRC agricultural sector.

\section{Methods}

Qualitative assessment through mapping tools is used for this case study to provide a rapid assessment of the capacity and incentive constraints faced by the actors and to suggest possible entry points for support used to analyze governance linkages, social networks, and implementation processes of programs and projects. Process-networkinfluence mapping (or simply Net-Map) is an interview-based mapping tool that helps users to understand, visualize, discuss, and improve situations in which many different actors influence outcomes (Schiffer 2007). This paper extends this by adding a series of interview questions about constraints faced by key actors and identifies whether these constraints are due to lack of capacity or lack of incentive.

A literature review on key organizations involved in the agricultural sector in DRC provided a tentative list of key officials or representatives who were contacted for interviews. The team started institutional mapping exercise with a key official at MINAGRI, which helped guide a snowball approach to selecting the subsequent interviewees. The study team conducted 26 interviews (with 46 key experts) in Kinshasa between May and September 2010. A total of 7 Net-Map interviews (with individuals or groups) and 19 semi-structured interviews (with individuals or groups) were conducted.

The Net-Map tool starts with a well-designed research question, expressed in the form of a final outcome or development objective. The focus is on the actors and their linkages, influence level, and capacity and incentive constraints in the actual recommendations and implementation of policy priorities stated in the Agricultural Code, Agricultural Policy Note, and Agricultural Strategy of DRC. The first phase of the mapping identified the key actors. Respondents described the policy processes step-by-step (from evidence-based research to actual funding and adoption of the policy) and identified the actors involved in each step.

The second phase involved mapping the linkages and interaction among the different actors. In communicating the definition to interviewees, the interviewers stressed that interaction or linkages can be in the form of funding, information flow, research, advice, advocacy, and reporting/authority and also asked respondents to describe the form of linkages they formed with other stakeholders. Those interviewed were asked to rate 
the level of this interaction using a 6 -point Likert scale $(1=$ no linkage, $2=$ very weak linkages, $3=$ weak linkages, $4=$ somewhat strong linkages, $5=$ strong linkages, $6=$ very strong linkages).

The third phase of the mapping involved asking respondents to rate the influence that different actors have on the actual policy process including recommendations and implementation in the Agricultural Code, Agricultural Policy Note, and Agricultural Strategy of DRC. To determine influence, the interviewers stressed that all types of influence are considered-financial, formal influence, communication, advice, or voicein determining the final influence level.

The rating was done on a scale from 0 to 6 and was visualized by using Checkers game pieces. As shown in Figure 2, the actors are indicated by the board game figures, and the Checkers game pieces are used to build towers, the height of which shows the influence level of the respective actors. This method has the advantage of visualizing influence levels in a three-dimensional space. While performing this exercise, the respondents were also asked to identify why different actors have the influence level ascribed to them.

For human capacity issues, respondents were asked to identify the strategic capacitystrengthening activity that would make the greatest positive impact in their organization. This emphasis during the interviews provided useful insights into the urgency and prioritization of investments in training needed to support the agricultural sector. Skill gaps and training needs had been identified by interviewees' self-evaluation.

All the results of the maps were consolidated into a single map. To capture the nuanced information attained through the interviews, the study team summarized the different maps drawn and the qualitative information gathered in the key informant interviews, taking into account the frequency with which actors and links were added and influences were attributed, the extent of involvement in the policy process of the respondents who added them, and the goals and possible biases of the particular respondents that may have affected their answers.

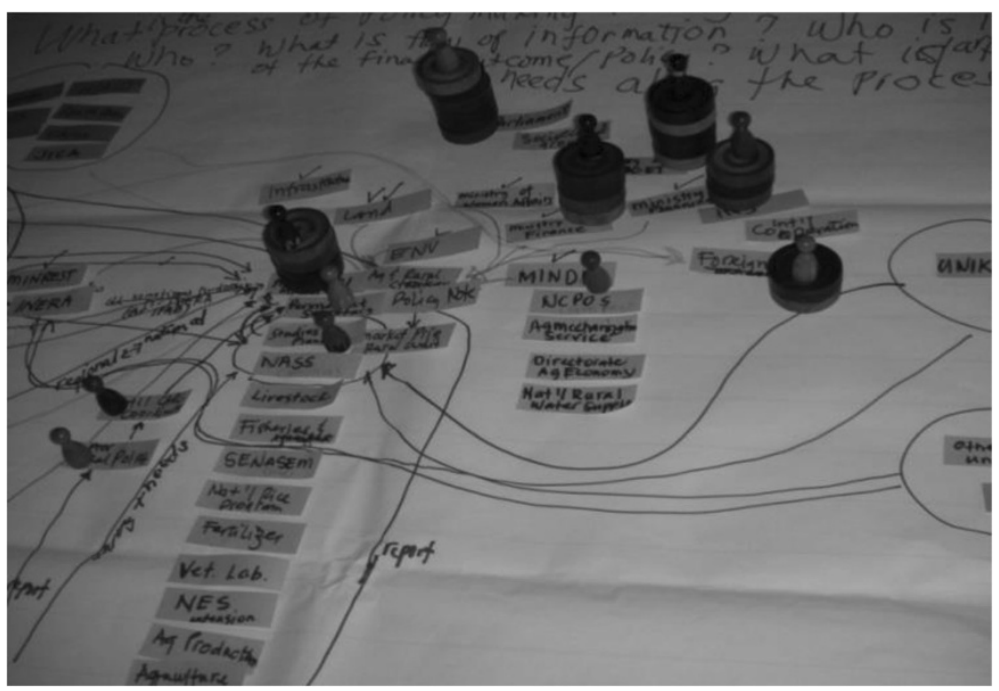

Figure 2 Net-Map of influence and power relation among key actors. 
The development of the final map can be described as an iterative process in which the study team collected the preliminary perception and information from existing literature, gathered information from a wide variety of actors involved in the policy process, drew a combined network map based on that information, and finally validated it by presenting and discussing it with key officials and experts in MINAGRI and other interviewees. The resulting map serves as a visual representation of the policy process and is used to illustrate the core actors, linkages, influence level, bottlenecks, incentives, and capacity constraints and for evidence-based and inclusive policy processes.

\section{Results and discussion}

Using the conceptual framework described in section 2, this section presents the results of the analysis of the data collected through the methods presented above.

\section{Organizational landscape}

Figure 3 presents the organizational landscape of the agricultural sector in DRC based on interviews with 45 high-level officials and representatives of the MINAGRI, the Ministry of Rural Development (MINRD ${ }^{\mathrm{d}}$ ), CARGs, parliament, development NGOs, the private sector, and universities.

Table 1 presents a summary of the roles of the different key organizations in the agricultural policy process. MINAGRI and MINRD are the two main ministries responsible for leading the agricultural strategy formulation and policymaking process in DRC. The

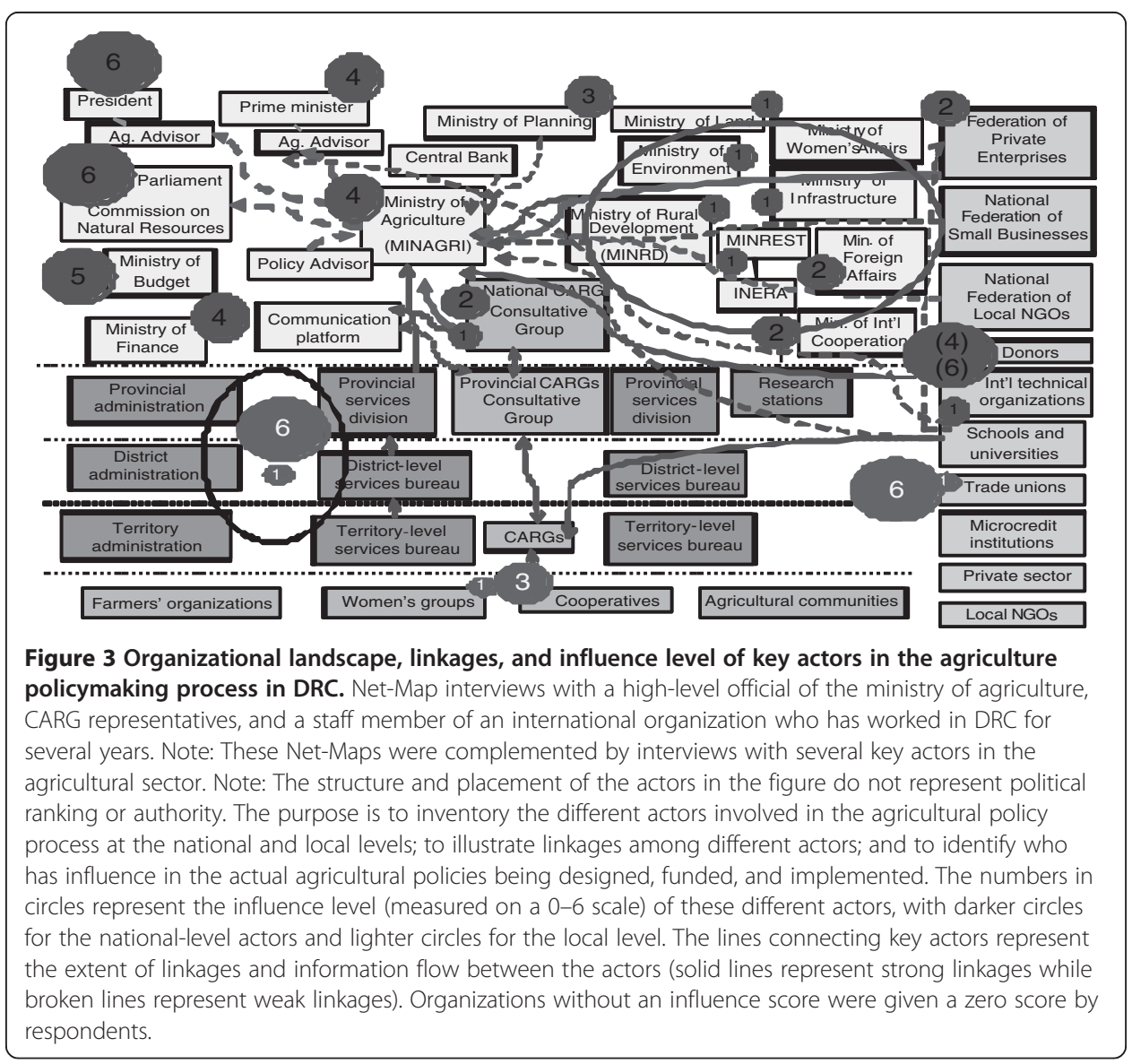


Table 1 Roles and influence level of different actors in the agricultural policymaking process in DRC

\begin{tabular}{|c|c|c|}
\hline Key organizations/individuals & Roles in policy process and source of influence & $\begin{array}{l}\text { Influence } \\
\text { level }\end{array}$ \\
\hline President, parliament & $\begin{array}{l}\text { They lead the national priorities, which in turn influence the } \\
\text { budget allocation and disbursement to the different } \\
\text { sectoral ministries and public services. }\end{array}$ & 6 \\
\hline Donors & $\begin{array}{l}\text { They provide support, through funding, advice, analytical } \\
\text { work, technical assistance, and capacity-strengthening } \\
\text { activities, among others. Due to limited local resource } \\
\text { mobilization, the government relies heavily on donor } \\
\text { funding. Given the lack of analytical capacity, the } \\
\text { government relies on analytical work and advice from } \\
\text { donors. The influence score assigned to donors vary } \\
\text { by interviewees. }\end{array}$ & $4-6$ \\
\hline Ministry of Budget & $\begin{array}{l}\text { It decides on actual budget allocation for the sector } \\
\text { ministries. }\end{array}$ & 5 \\
\hline Ministry of Finance & It sets priorities on actual budget disbursement. & 4 \\
\hline MINAGRI & $\begin{array}{l}\text { It coordinates the consultative process, design, drafting, } \\
\text { implementation, and monitoring of policies, strategies, and } \\
\text { plans for the agricultural sector; it leads the resource and } \\
\text { political support mobilization. }\end{array}$ & 4 \\
\hline Prime Minister & $\begin{array}{l}\text { Together with the president, the prime minister leads the } \\
\text { country and oversees national priority setting. }\end{array}$ & 3 \\
\hline Ministry Planning & $\begin{array}{l}\text { It sets the national economic plan that affects agricultural } \\
\text { strategies, programs, and budget. }\end{array}$ & 3 \\
\hline $\begin{array}{l}\text { Federation of Private Enterprises } \\
\text { (Federation des Enterprises du Congo, } \\
\text { or FEC) }\end{array}$ & $\begin{array}{l}\text { This serves as a forum for dialogue among larger private- } \\
\text { sector firms and a platform for advocating their concerns, } \\
\text { needs, and priorities to MINAGRI in particular and policy } \\
\text { processes in general. }\end{array}$ & 2 \\
\hline CARG & $\begin{array}{l}\text { It is a platform for policy dialogues and discussions, sharing } \\
\text { problems and jointly finding solutions, setting priorities and } \\
\text { strategies at the local level, and advocating for local } \\
\text { demands and needs at the national policy level. }\end{array}$ & $1-2$ \\
\hline $\begin{array}{l}\text { MINRD, Ministry of Land, Ministry of } \\
\text { Infrastructure, Ministry of Research, } \\
\text { and others }\end{array}$ & $\begin{array}{l}\text { MINRD is responsible for community development, rural } \\
\text { roads/feeder roads, small rivers, rural water supply, and rural } \\
\text { housing. All of these ministries provide inputs to policy } \\
\text { design and lead the implementation of activities and } \\
\text { programs specific to the ministries' mandates. }\end{array}$ & 1 \\
\hline $\begin{array}{l}\text { International technical organizations } \\
\text { (FAO, IFPRI, other CGIAR centers) }\end{array}$ & $\begin{array}{l}\text { They provide technical support to the many functions of } \\
\text { MINAGRI and other ministries. }\end{array}$ & 1 \\
\hline $\begin{array}{l}\text { Ministry of International Cooperation, } \\
\text { Ministry of Foreign Affairs }\end{array}$ & $\begin{array}{l}\text { They facilitate and manage the international partnerships in } \\
\text { DRC. }\end{array}$ & 1 \\
\hline $\begin{array}{l}\text { Universities (UNIKIN, University of } \\
\text { Lubumbashi, University of Yangambi, } \\
\text { and UCC) }\end{array}$ & $\begin{array}{l}\text { They are tasked to provide research and technical advice } \\
\text { on policy options. However, they are not currently linked to } \\
\text { MINAGRI and other ministries or policy processes. }\end{array}$ & 0 \\
\hline $\begin{array}{l}\text { Agricultural education and training } \\
\text { institutes }\end{array}$ & $\begin{array}{l}\text { They are tasked to train educators, researchers, extension } \\
\text { agents, and professionals to work for the sector } \\
\text { (government, private sector, NGOs, etc.). However, they do } \\
\text { not have a voice and direct engagement in the actual } \\
\text { policy process. }\end{array}$ & 0 \\
\hline $\begin{array}{l}\text { COPEMECO and other national } \\
\text { federations }\end{array}$ & $\begin{array}{l}\text { They are tasked to represent the interest of small business, } \\
\text { farmers' organizations, and civil society at large. However, } \\
\text { they do not have a voice in the actual policy decisions. }\end{array}$ & 0 \\
\hline
\end{tabular}

Source: Author's interviews and Net-Maps.

political system that conditions the financial resources and enabling environment for the agricultural sector includes the President, Prime Minister, and parliament at the national level and elected government administrators at the local level. Political parties play a role in the selection of candidates for elected and appointed positions at local 
and national levels. They can also be involved in the recruitment and promotion of staff in the public sector.

The government ministries are responsible, each in its area of intervention, for policy, planning, implementation, and monitoring of development programs. In total, there are 11 provinces (including the capital city Kinshasa), 30 districts, ${ }^{\mathrm{e}} 145$ territories, and 800 sectors (formerly called collectivities) in DRC. Within the decentralization process, the provincial services of the ministries are being revitalized to better serve the rural population. Staff recruitment to support the decentralized units is ongoing.

A number of universities perform some agricultural economic and rural development research, namely, University of Kinshasa (UNIKIN), University of Lubumbashi, University of Yangambi, and the Catholic University of Congo (UCC). International organizations provide technical assistance and analytical support, sometimes in collaboration with these local universities. The main donors for the agricultural sector in DRC include the BTC, World Bank, European Union, and USAID.

Farming communities and their organizations are crucial players in the agricultural sector. The three federations of NGOs-the Federation of Laic and Economic NGOs (FOLECO), CNONGD and the Regional Council of Development NGOs (CRONGD) have so far not gained a strong influence in the agricultural policymaking processes. For a more systematic engagement of civil society organizations into policymaking and planning processes, the government initiated in 2008 the creation of CARGs, which are the platforms for multi-stakeholder discussions and dialogues toward the development of agricultural plans at the territorial, provincial, and national levels. Private-sector participation in the agricultural policymaking process in DRC has not been strong in the past years, except for some advocacy efforts by the FEC (Federation of Private Enterprises in Congo). Similarly, the Confederation of Small and Medium Enterprises of the Congo (COPEMECO), of which numerous small-scale enterprises are members, have not gained a strong presence in the agricultural policymaking process in the past.

\section{Influence}

Understanding the influence level of each organization in the policy and institutional reforms process is important to identify feasible entry points for intervention; to prioritize capacity and incentive gaps; and to identify weaknesses in information flow and links between research-based evidence and decision-making process. As indicated in Figure 3 and Table 1, high-level policy- and lawmakers (the President and the Members of Parliament) were given the highest influence score (6) because they set national priorities, which in turn influence the budget allocation and disbursement to the different sectorial ministries and public services. The next most influential is the Ministry of Budget, which decides on actual budget allocation for the sector ministries, with an influence score of 5, followed by the Ministry of Finance, which sets priorities on actual budget disbursement (influence score $=4$ ). The prime minister also has strong influence in setting national priorities and agricultural policies. Depending on the interviewer, the donors in general were given a score of 4 or 6 in terms of their level of influence.

The MINAGRI is responsible for leading the agricultural strategy formulation and policymaking process in DRC (influence score $=4$ ), while other relevant ministries, such as MINRD, provide inputs and support (collective influence score $=1$ ). FEC was singled out as influential in the actual policies formulated in MINAGRI (influence score $=2$ ), 
while civil society, through the CARGs, also has only small influence in the actual policy formulation to date (influence score $=1-2$ ). The Ministry of International Cooperation and Ministry of Foreign Affairs, which facilitate and manage the international partnerships in DRC, were given a score of 2 in terms of influence, while international technical organizations (particularly FAO and other UN agencies) were given an influence score of 1 . These patterns of influence suggest that greater attention is needed to ensure that compelling evidence from research reaches the influential decision-makers and funders. This will require strengthening policy dialogue and negotiation skills, among many other skills and competencies. It may also require more systematic mechanisms of linking MINAGRI and these decision-makers, such as initiating regular meetings with the agriculture advisors of the president and prime minister, and to examine the re-establishment of the socioeconomic research committee, with emphasis on the agriculture and rural sectors, at the parliament.

At the provincial level, members, coordinators, focal points of CARGs and representatives of MINAGRI were asked to rate the level of influence of the different actors at the provincial and territory levels on the local agricultural policy outcomes (lighter circles in Figure 3). Respondents highlighted that experiences across provinces and territories vary. Within CARGs, in theory the level of influence should be in favor of the civil society as it represents two-thirds of the membership, with the government having one-third. In reality for many places, the most influential (with a score of 6) are still the government and/or ministry officials at provincial and territory levels, while in some areas the most influential (with a score of 6) are trade unions. The level of influence by the government and trade unions can also score as low as 1 depending on the provinces and territories according to key informants. There is some influence by the producer's association and civil society organizations through CARGs, with a score of 1 to 3 depending on the province or territory. Respondents indicate an improvement in the civil society participation compared with previous years, and they are hopeful that it will continue to improve as the implementation of and support for CARGs goes into full speed. The CARG guidelines also indicate that one-third of CARG membership should be women, but either lack of women leaders or inability of women leaders to attend CARG-related meetings and workshops hinders the realization of this quota of participation in CARGs.

The pattern of influence at the local level suggests the need to strengthen civil society organizations so that they would be able to participate more effectively and benefit in platforms and networks, such as CARGs. Capacity strengthening will also be needed by public-sector organizations as they remain major players that lead, guide, and influence CARG functioning. CARGs depend on the capacity and strength of the members organizations. The Net-Map exercise suggests that experiences differ by provinces and territories, so further studies will be needed to understand influence level, actual functioning, and impact of CARGs. Further analysis will also be needed to study the constraints of women in participating in CARGs and to identify whether this is a constraint in the effective and sustainable functioning of CARGs.

\section{Linkages}

Table 2 provides the linkage scores among organizations rated by respondents from different organizations in DRC. Key informants have highlighted a number of weaknesses 
Table 2 Degree of linkages among organizations in the agricultural policy process

\begin{tabular}{lcccc}
\hline Linkage & $\begin{array}{c}\text { Avg. } \\
\text { score* }\end{array}$ & $\begin{array}{c}\text { Std. } \\
\text { dev. }\end{array}$ & Min. & Max. \\
\hline Between MINAGRI and INERA & 4.8 & 0.9 & 3.0 & 6.0 \\
\hline Between MINAGRI and CARG & 4.6 & 1.0 & 3.0 & 6.0 \\
\hline Between MINAGRI and international partners & 4.5 & 1.1 & 2.0 & 6.0 \\
\hline Between INERA and universities & 4.2 & 1.2 & 2.0 & 6.0 \\
\hline Between MINAGRI and MINRD & 4.1 & 1.2 & 2.0 & 6.0 \\
\hline Between MINAGRI and Ministry of Planning & 4.0 & 1.2 & 2.0 & 6.0 \\
\hline Between MINAGRI and Min. of Finance/Budget & 3.9 & 1.0 & 3.0 & 6.0 \\
\hline Among universities & 3.9 & 1.2 & 2.0 & 5.0 \\
\hline Between national-level and local-level MINAGRI & 4.0 & 1.3 & 1.0 & 6.0 \\
\hline Between national-level and local-level MINRD & 3.8 & 1.1 & 2.0 & 6.0 \\
\hline Between universities and international partners & 3.8 & 1.3 & 2.0 & 6.0 \\
\hline Between MINAGRI and offices of president, prime minister, and parliament & 3.7 & 1.0 & 2.0 & 6.0 \\
\hline Between MINAGRI and NGOs & 3.6 & 1.3 & 1.0 & 5.0 \\
\hline Between MINAGRI and universities & 3.6 & 1.2 & 1.0 & 5.0 \\
\hline Between MINAGRI and other ministries & 3.5 & 1.3 & 1.0 & 5.0 \\
\hline Between CARGs and NGOs at local levels & 3.5 & 0.8 & 2.0 & 5.0 \\
\hline Between MINAGRI and private sector & 3.4 & 0.7 & 2.0 & 5.0 \\
\hline Between CARGs and CRONGD and CNONGD & 3.3 & 1.2 & 1.0 & 5.0 \\
\hline Between CARGs and FEC & 3.3 & 1.2 & 1.0 & 5.0 \\
\hline Between CARGs and FOLECO & 3.2 & 1.0 & 1.0 & 5.0 \\
\hline Between CARGs and COPEMECO & 3.1 & 1.3 & 1.0 & 5.0 \\
\hline Between CARGs and INERA & 2.8 & 1.1 & 1.0 & 5.0 \\
\hline Between CARGs and universities & 0.9 & 1.0 & 5.0 \\
\hline Between universities and private sector & & & \\
\hline Source: Auts complla
\end{tabular}

Source: Authors' compilation based respondents.

Note: * Interviewees were asked to rate the level of interaction and linkages between various organizations using a 6point Likert scale ( $1=$ no linkage, $2=$ very weak linkages, $3=$ weak linkages, $4=$ somewhat strong linkages, $5=$ strong linkages, $6=$ very strong linkages).

in the interaction and linkages among actors in the agricultural landscape (illustrated by the broken lines in Figure 3). Overall, MINAGRI's linkage with other organizations involved in the policy processes in DRC is weak. The major missed opportunity is between policy analysis and the highest levels of influence. As indicated above, the national decision-makers (including the president, parliament, and prime minister) are not reached systematically by sources of evidence and cutting-edge research on the role and importance of the agricultural sector and on viable options and priorities of advancing the sector. Although the offices of the president and prime minister do have agriculture advisors, key informants suggest only weak interaction between them and MINAGRI. There is also a commission in the parliament that looks at agriculture and natural resources policies, but key informants also suggest a weak linkage between members of this commission and MINAGRI. In Table 2, an average linkage score of 3.7 (out of 6), which ranges from weak to somewhat strong linkage, indicates a huge space for improvement to fill the research-policy-action gap. Moreover, the agencies that decide on budget allocations and actual disbursements are not systematically reached by convincing and compelling evidence of investing in the sector as well as by advocacy and lobbying that make the case for increased investment in agriculture (mean linkage score $=3.9$ ). This 
influence-linkage analysis highlights the mismatch between sources of research and sources of influence, which appears to be a major hurdle in evidence-based planning in DRC.

The two main ministries that lead the agricultural and rural sectors, MINAGRI and MINRD, have some degree of coordination (mean linkage score $=4.1$ ), but respondents indicated that this could be improved by clarifying roles and responsibilities for each ministry and communicating ongoing reform and change processes.

In terms of priority setting and strategic planning, MINAGRI gets technical inputs from the inter-ministerial committee, although with limited interaction (mean linkage score = 3.6). MINAGRI sources its evidence-based analysis from international organizations (e.g., World Bank, FAO, BTC, and IFPRI) and has relatively strong linkages with these partners (mean linkage score $=4.5$ ). Both MINAGRI and MINRD get agricultural data through the statistical and data-collection systems in the provincial and territory services units, but interaction and coordination between national and local units in these ministries remain limited (mean linkage score $=3.8-4.0$ ). They receive feedback on problems and needs of the rural population through the CARGs platform, which are part of MINAGRI (mean score linkage $=4.6$ ); but there is limited interaction between MINAGRI or MINRD and FEC (mean linkage score $=3.4$ ) and the federation of NGOs (mean linkage score $=3.7$ ).

In terms of evidence-based analysis, the capacity at MINAGRI is weak, but the capacity for economic and policy research in other organizations (universities, Central Bank's Economic Research Department, and Ministry of Planning) is relatively stronger (Table 3). The issue is that the linkage between the ministry and these organizations with capacity is weak to somewhat strong (mean linkage scores $=3.6-4.0$ ). Key informants indicate that this limited interaction is due to lack of trust from both sides and lack of incentive to interact as dictated by a different set of performance indicators in these organizations. Currently, there is no capacity at MINAGRI to initiate or facilitate such interaction and linkage. On the other hand, the linkage between MINAGRI and INERA seems to be stronger for scientific research (mean linkage score $=4.8$ ). MINAGRI should use this example to follow in strengthening interactions with other research organizations and universities.

Universities have started to be actively involved in providing results of analytical work through the organized technical workshops within CARGs in relation to the provincial agricultural plan formulation. However, outside this mechanism, there are no other informal or formal linkages between universities and members of the CARGs. While there is stronger interaction within universities (mean linkage score $=3.9$ ) and between universities and INERA (mean linkage score $=4.2$ ), there are weak linkages between these universities and CARGs (mean linkage score $=2.8$ ) and between universities and the private sector (mean linkage score $=2.8$ ). Universities have only limited opportunities for research and consultancy with international partners (mean linkage score $=3.8$ ). Interviews also suggest weak linkages between universities and other ministries and publicsector agencies. Moreover, policy advisors of MINAGRI are responsible for providing cutting-edge and up-to-date advice in the ministry, but insights from the interviews suggest that there is limited interaction between policy advisors of the minister and universities and sources of analytical work. Similarly, agricultural policy advisors inform the president and prime minister, but they are currently not linked to the universities, ministry of agriculture, or sources of information and analytical work. 
Table 3 Capacity levels of key organizations in the agricultural policy processes

\begin{tabular}{|c|c|c|c|c|c|c|c|c|c|c|}
\hline \multirow[t]{2}{*}{$\begin{array}{l}\text { Capacity/ } \\
\text { Organization }\end{array}$} & \multicolumn{2}{|c|}{$\begin{array}{l}\text { Human } \\
\text { capacity }\end{array}$} & \multicolumn{2}{|c|}{$\begin{array}{l}\text { Facilities and } \\
\text { infrastructure }\end{array}$} & \multicolumn{2}{|c|}{$\begin{array}{c}\text { Organizational } \\
\text { procedures and } \\
\text { management } \\
\text { systems }\end{array}$} & \multicolumn{2}{|c|}{$\begin{array}{c}\text { Monitoring } \\
\text { and evaluation } \\
\text { system }\end{array}$} & \multicolumn{2}{|c|}{$\begin{array}{c}\text { Coordination and } \\
\text { communication } \\
\text { systems }\end{array}$} \\
\hline & $\begin{array}{l}\text { Avg. } \\
\text { score* }\end{array}$ & $\begin{array}{l}\text { Std. } \\
\text { dev. }\end{array}$ & $\begin{array}{l}\text { Avg. } \\
\text { score }\end{array}$ & $\begin{array}{l}\text { Std. } \\
\text { dev. }\end{array}$ & $\begin{array}{l}\text { Avg. } \\
\text { score }\end{array}$ & $\begin{array}{l}\text { Std. } \\
\text { dev. }\end{array}$ & $\begin{array}{l}\text { Avg. } \\
\text { score }\end{array}$ & $\begin{array}{l}\text { Std. } \\
\text { dev. }\end{array}$ & $\begin{array}{l}\text { Avg. } \\
\text { score }\end{array}$ & $\begin{array}{l}\text { Std. } \\
\text { dev. }\end{array}$ \\
\hline Overall & 3.8 & 1.2 & 3.2 & 1.2 & 3.3 & 1.1 & 3.0 & 1.2 & 3.3 & 1.1 \\
\hline \multicolumn{11}{|l|}{ Main universities } \\
\hline$\overline{U N I K I N}$ & 4.6 & 1.1 & 3.7 & 1.3 & 3.6 & 1.2 & 3.3 & 1.3 & 3.6 & 1.3 \\
\hline$\overline{U C C}$ & 4.5 & 1.0 & 4.3 & 1.3 & 4.0 & 1.1 & 4.1 & 1.1 & 4.0 & 1.2 \\
\hline U. of Yangambi & 3.8 & 1.1 & 3.1 & 1.4 & 3.3 & 1.0 & 3.1 & 1.2 & 3.1 & 1.3 \\
\hline U. of Lubumbashi & 4.3 & 1.2 & 3.5 & 1.2 & 3.5 & 1.3 & 3.2 & 1.5 & 3.3 & 1.4 \\
\hline
\end{tabular}

Main government ministries and agencies

\begin{tabular}{|c|c|c|c|c|c|c|c|c|c|c|}
\hline MINAGRI—national & 4.1 & 1.2 & 3.2 & 1.2 & 3.1 & 1.1 & 2.8 & 1.3 & 3.0 & 1.0 \\
\hline MINAGRI—local & 3.2 & 1.1 & 2.5 & 1.2 & 2.5 & 0.9 & 2.3 & 1.1 & 2.6 & 0.9 \\
\hline MINRD—national & 3.4 & 1.1 & 2.6 & 1.1 & 2.7 & 1.0 & 2.4 & 1.1 & 2.7 & 0.9 \\
\hline MINRD_local & 2.9 & 1.4 & 2.3 & 1.0 & 2.7 & 1.0 & 2.3 & 1.2 & 2.4 & 1.0 \\
\hline Ministry of Land & 3.8 & 1.2 & 3.0 & 1.3 & 3.1 & 1.3 & 2.8 & 1.4 & 3.0 & 1.2 \\
\hline MINREST & 3.6 & 1.4 & 2.9 & 1.3 & 3.1 & 1.3 & 2.8 & 1.4 & 3.2 & 1.3 \\
\hline $\begin{array}{l}\text { Ministry of } \\
\text { Environment }\end{array}$ & 4.1 & 1.3 & 3.4 & 1.4 & 3.5 & 1.3 & 3.1 & 1.5 & 3.3 & 1.3 \\
\hline Ministry of Finance & 4.1 & 1.2 & 3.8 & 1.3 & 3.5 & 1.3 & 3.1 & 1.5 & 3.6 & 1.1 \\
\hline Ministry of Planning & 4.2 & 0.9 & 3.6 & 1.2 & 3.6 & 1.1 & 3.3 & 1.4 & 3.7 & 1.0 \\
\hline $\begin{array}{l}\text { Ministry of } \\
\text { Infrastructure }\end{array}$ & 3.8 & 1.0 & 3.3 & 1.1 & 3.4 & 1.1 & 2.9 & 1.2 & 3.1 & 1.3 \\
\hline $\begin{array}{l}\text { Ministry of Women } \\
\text { Affairs }\end{array}$ & 3.6 & 1.5 & 3.3 & 1.8 & 3.4 & 1.4 & 3.0 & 1.5 & 3.3 & 1.4 \\
\hline $\begin{array}{l}\text { Central Bank, Economic } \\
\text { Research Dept. }\end{array}$ & 4.5 & 1.1 & 4.2 & 1.0 & 4.0 & 1.2 & 3.8 & 1.1 & 4.4 & 1.0 \\
\hline
\end{tabular}

Main platforms and associations

\begin{tabular}{lllllllllll}
\hline CARG & 3.4 & 1.1 & 2.6 & 0.9 & 3.0 & 1.1 & 2.8 & 0.9 & 3.3 & 1.2 \\
\hline FEC & 3.9 & 1.2 & 3.2 & 1.1 & 3.6 & 1.1 & 3.4 & 1.1 & 3.6 & 1.1 \\
\hline COPEMECO & 3.5 & 1.1 & 2.8 & 1.0 & 3.1 & 1.0 & 2.9 & 0.9 & 3.2 & 1.1 \\
\hline FOLECO & 3.7 & 1.1 & 2.9 & 1.0 & 3.2 & 1.1 & 3.1 & 1.2 & 3.5 & 1.1 \\
\hline CNONGD & 3.6 & 1.1 & 2.8 & 1.1 & 3.0 & 1.0 & 2.9 & 1.0 & 3.2 & 1.0 \\
\hline CRONGD & 3.6 & 1.1 & 2.7 & 0.9 & 3.0 & 0.9 & 3.1 & 1.0 & 3.2 & 1.0 \\
\hline
\end{tabular}

Source: Authors' compilation based on respondents. Notes: *Rating is based on a scale from 1 to 6 (where $1=$ no linkages and $6=$ very strong linkages). The figures are the mean scores of Net-Map interviewees and 18 respondents from different organizations in DRC, based on a semistructured questionnaire administered during the training on policy analysis on December 16, 2010.

\section{Organizational capacity}

Table 3 presents perceptions of stakeholders on the level of capacity of key organizations in the agricultural sector. Results suggest stronger human capacity in the universities especially UNIKIN, UCC, and University of Lubumbashi and in the Central Bank's Economic Research Department and the Ministry of Planning. Human capacity is weak at MINRD (national and local levels) and MINAGRI (local level). Of all the platforms and associations, CARG has the weakest human capacity while FEC has the highest score.

Unlike human capacity, the other areas of capacity (including facilities and infrastructure, organizational systems, M\&E, and coordination and communication within 
organization) were rated to be weak or very weak by the respondents. Only UCC, Ministry of Finance, Ministry of Planning, Central Bank, and FEC have somewhat strong capacity in these areas. The weakest ones are the MINRD (national and local levels), MINAGRI (national and local levels), CARGs, Ministry of Land, MINREST, and Ministry of Women's Affairs.

Of particular interest are the universities and research organizations that provide evidence-based analysis and planning for the ministries. The university system faces numerous challenges including a disconnect between teaching, training and research on the one hand and policy problems and realities in the field on the other. Lack of investment and funding in university systems results in insufficient facilities, computer centers, and training materials and decaying human capital. Training of staff should be accompanied by upgrades in university infrastructure and equipment.

\section{Human capacity}

The current structure of the human resources in the agricultural sector is characterized by dichotomy of staff, with older staff at retiring age on one end and very junior staff with only bachelor's degrees or lower on the other. Qualifications and training of professional staff are generally low in MINAGRI, MINRD, and other key organizations in the agricultural sector. Hiring adequate staff and long-term training (master's and doctorate's degree programs) for junior staff will be required.

\section{Analytical capacity}

Human capacity in policy research and analysis is limited. Only about $13 \mathrm{PhDs}$-at UNIKIN, University of Yangambi, and UCC-are working on agricultural economics and rural development research for DRC's estimated population of 68 million. This figure is low compared with other African countries. For example, in Malawi, experts estimate around $50 \mathrm{PhDs}$ working on agricultural economics and rural development research for an estimated 13 million population (IFPRI International Food Policy Research Institute 2012). There is a serious lack of policy analytical capacity at MINAGRI and MINRD. A diagnostic survey was administered to potential policy analysts in MINAGRI, MINRD, Ministry of Planning, Ministry of Land, INERA, Central Bank's Economic Research Department, and universities; and the 11 questionnaires that the team received back indicate limited knowledge in statistics and research methods, limited application of statistical techniques, and limited background in computer applications and software (Table 4). Those with a relative better perception of their proficiency are from the universities. The insufficient computer facilities contribute to this weak capacity of staff and their organizations. Substantive training as well as collaboration within existing

Table 4 Distribution of respondents based on proficiency in computer applications

\begin{tabular}{lccccc}
\hline Proficiency & No experience & Limited & Average & Good & Very good \\
\hline Use of computer & 0 & 3 & 3 & 3 & 2 \\
MS Excel & 0 & 5 & 0 & 5 & 1 \\
Eviews & 7 & 2 & 0 & 2 & 0 \\
SPSS & 5 & 5 & 0 & 1 & 0 \\
Stata & 9 & 2 & 0 & 0 & 0 \\
\hline
\end{tabular}

Source: Author's compilation based on diagnostic evaluation of potential trainees on policy analysis. 
capacity is needed for policy research. Training of staff should be accompanied by upgrades in infrastructure and equipment.

Provincial agricultural plans are the basis for a national plan. With decentralization, policy processes and decision-making are being conducted at the local level. It is important to build decentralized capacity for evidence-based policy analysis at the local level. Analytical skills for developing evidence based provincial plans and strategies are critically needed if the CARG approach to agricultural development is to succeed. While some capacity-strengthening activities exist at the national level (e.g., those conducted by FAO [FAO Food and Agriculture Organization of the United Nations 2008], the profound capacity gaps at the provincial level are yet to be addressed.

\section{Policy dialogues and consultative processes}

Several interviews with experts indicate serious problems in policy dialogue and consultation processes. First, consistently mentioned by all interviewees is the need for skills development on policy dialogue, communication, and negotiation. Second, key informants indicated lack of awareness and information on the status of reforms. One commonly mentioned example is the split between MINAGRI and MINRD, in which a number of respondents have some confusion on the division of functions. This hinders officials' and employees' understanding of their respective roles and responsibilities, limiting their incentive to perform. Some have concerns that the split will make coordination of agricultural and rural development policies on the ground more difficult. The reform coordination unit can include public awareness and reform communication strategies as an urgent activity. The extent of understanding and awareness by the public should also be one of the indicators of the success of the reform process that can be collected. The M\&E system to be adopted by the reform coordination unit should be a result of an open and inclusive consultation. The communication platform and CARGs can be used as platforms for disseminating information about specifics and status of reform processes.

\section{Monitoring and evaluation}

$M \& E$ is one of the seriously neglected key processes in the agricultural sector. MINAGRI does not have a M\&E system. The statistical office compiles data on agricultural production from territory levels. Each technical directorate will report this to the key officials of the ministry. The directorate of planning and studies at MINAGRI is tasked with M\&E. Although there is one person in charge of M\&E, there is no framework or plan in place. Other divisions of MINAGRI and other ministries confirmed that no work plans or performance-based evaluation system is in place.

\section{Coordinated capacity development efforts}

Key informants and a review of gray literature indicate numerous training and capacitybuilding efforts being conducted and implemented in DRC in various sectors including agriculture. While substantial donor resources are allocated to these trainings, still they are not institutionalized and have no sustainability mechanism. Agricultural training institutes and higher education institutes are often not involved in the training and capacity building being provided. 


\section{Organizational culture and incentives}

Organizational culture in the agriculture organizations in DRC can be characterized by weak incentives to perform, fragile work environment, and lack of accountability as a result of the lack of capacity, incentive structures, and management systems described above. Table 5 provides a summary of the scores on perception of organizational culture. Respondents rated self-esteem and employee morale relatively high. Respondents also rated the quality of leaders and supervisors in their organization relatively high. Measures of transparency, fairness, political autonomy, coherence, openness, responsiveness, and flexibility were rated quite high on average, although answers vary widely among respondents. In contrast, measures of adequacy of resources, efficiency, freedom from corruption, job security, and mobility were rated low. Manifestations and sources of these disincentives among leaders and staff of key organizations include the following:

\section{Weak political commitment}

Agriculture is considered one of the "priority sectors" in government programs, in addition to education and health. In 2004, the government also promised at least 10 percent of public investments in agriculture. Despite this rhetoric, the budget allocated

Table 5 Perception of work environment, different organizations in DRC, 2010

\begin{tabular}{|c|c|c|c|c|}
\hline Statement on work environment & $\begin{array}{l}\text { Avg. } \\
\text { score* }\end{array}$ & $\begin{array}{l}\text { Std. } \\
\text { dev. }\end{array}$ & Min. & Max. \\
\hline You feel recognized by your boss and co-workers as a hard worker. & 1.3 & 0.5 & 1.0 & 2.0 \\
\hline You are satisfied with your job. & 1.6 & 0.6 & 1.0 & 3.0 \\
\hline The head of your organization is dynamic, inspirational, and respectful. & 1.8 & 0.8 & 1.0 & 4.0 \\
\hline $\begin{array}{l}\text { Your supervisor or boss knows enough about your daily activities to know if } \\
\text { you are doing good or poor work. }\end{array}$ & 1.9 & 0.5 & 1.0 & 3.0 \\
\hline $\begin{array}{l}\text { Complaints from clients or partners are taken very seriously in this } \\
\text { organization. }\end{array}$ & 2.0 & 0.4 & 1.0 & 3.0 \\
\hline $\begin{array}{l}\text { Your supervisor or boss consults you or asks your opinion regarding important } \\
\text { changes. }\end{array}$ & 2.0 & 0.8 & 1.0 & 4.0 \\
\hline There are good opportunities for promotion in your organization. & 2.1 & 0.7 & 1.0 & 4.0 \\
\hline $\begin{array}{l}\text { Your supervisor or boss gives you considerable opportunity for independence } \\
\text { and freedom. }\end{array}$ & 2.1 & 0.7 & 1.0 & 4.0 \\
\hline Performance evaluation in your organization is carried out in a fair way. & 2.1 & 0.8 & 1.0 & 3.0 \\
\hline $\begin{array}{l}\text { Male and female staff in your organization have equal opportunities in getting } \\
\text { promoted. }\end{array}$ & 2.1 & 0.8 & 1.0 & 4.0 \\
\hline There is hardly any political interference in our work. & 2.1 & 1.1 & 1.0 & 4.0 \\
\hline The majority of people in your organization are well-qualified to do their job. & 2.4 & 0.9 & 1.0 & 4.0 \\
\hline Your organization's staff are hired and promoted purely on the basis of merit. & 2.4 & 0.8 & 1.0 & 4.0 \\
\hline $\begin{array}{l}\text { In your organization, everyone has a clear understanding of their tasks and } \\
\text { functions. }\end{array}$ & 2.4 & 0.5 & 2.0 & 3.0 \\
\hline $\begin{array}{l}\text { Clients or partners never complain about the performance of your } \\
\text { organization. }\end{array}$ & 2.5 & 0.7 & 1.0 & 4.0 \\
\hline Mobility to your operational area is easy. & 2.6 & 1.0 & 1.0 & 4.0 \\
\hline $\begin{array}{l}\text { Staff in your organization have to be worried about losing their jobs in the } \\
\text { near future. }\end{array}$ & 2.9 & 0.8 & 1.0 & 4.0 \\
\hline Corruption or misuse of funds is not a problem in your organization. & 2.9 & 0.8 & 2.0 & 4.0 \\
\hline Your organization is effective given its budget. & 3.0 & 1.0 & 1.0 & 4.0 \\
\hline
\end{tabular}

Source: Authors' compilation based on respondents.

Notes: *Rating is based on a scale from 1 to 4 (where $1=$ strongly agree, $2=$ agree, $3=$ disagree, $4=$ strongly disagree). The figures are the mean scores of Net-Map interviewees and 18 respondents from different organizations in DRC, based on a semistructured questionnaire administered during the training on policy analysis on December 16, 2010. 
to agriculture is well below the 10 percent recommended by the Maputo agreement. In 2007, the budget rate allocated to the agricultural sector was approximately 1.2 percent. It has decreased every year and has dropped to 0.7 percent in 2009 (MINAGRI reports cited by SADC Southern African Development Community 2009).

\section{Lack of strategic direction and measurable targets}

MINAGRI is still in the process of designing its overall agricultural strategy and plan, and these efforts have to be geared up within the new platform of CARGs. Unless such vision and concrete goals are produced, efforts to develop the sector will remain scattered and uncoordinated. The lack of human capacity at MINAGRI constrains effective agricultural planning and strategy formulation. The ministry has recently produced the DRC Agriculture Code and Agriculture Policy Note, which describe a general situation of the potential and constraints of the sector and provide an overall direction in terms of what the sector wants to achieve. But these documents do not contain any concrete goals or measurable targets. Furthermore, they do not consolidate efforts toward specific outputs and outcomes that can be validated, monitored, and evaluated over time.

\section{Accountability measures}

As already mentioned, MINAGRI has no M\&E systems. At the CARG level, a document includes some indicators for CARG performance, but it pertains only to output indicators such as membership and attendance in meetings without mention of any outcome or impact indicators. The lack of information on tangible results to its members can hinder the sustainability and scaling up of good practices across CARGs. The reform coordination unit should review M\&E systems of relevant organizations and make capacity-building for M\&E systems a priority action.

\section{Incentive constraints in CARGs}

The formation of CARG shows both capacity and incentive issues. Areas of capacity gap range from negotiation and policy dialogue skills, organizational and management skills to competencies in marketing, processing, and value addition and M\&E. Two meetings with CARG representatives by the study team and samples of meeting minutes reveal that key incentive problems faced by CARG formation include low attendance in meetings, weak connection with service providers, time and commitment of the executive secretary, sustainability of funds, and level of influence and power.

\section{Individual incentives}

Incentive for staff to stay in the public sector is limited. Pay is seriously low compared with the private sector and with the public sectors in other countries, which limits motivation and seriousness at work. High-level professionals earn less than US\$20 per month in the provinces and a maximum of US $\$ 45$ in Kinshasa, but the bulk of staff earn US $\$ 5$ to US\$15 a month (World Bank 2006). Field allowances generally are not paid.

Official statistics reveal that the nominal wage index in the private sector has increased by 23-78 percent from 2005 to 2007, while the public-sector wage index remained stagnant; and the real wage index in the private sector increased by $8-53$ percent, while the real wage index in the public sector decreased by 11-17 percent during 2005-2007 (BCC Bangue Centrale du Congo [Central Bank of Congo]). Wages 
generally are paid two to three months late; and some areas affected by armed conflict, such as North and South Kivu and Maniema, as of 2005 had not been paid for three years (World Bank 2006). MINAGRI can play a role in advocating for speedier civil service and salary reform.

\section{Discussions and policy implications}

A number of lessons emerge for strengthening the policy processes for agricultural development in DRC.

Investing inhuman capital and strengthening institutional linkages

The government must invest in hiring the minimum required number of staff and skill sets, minimum facility and infrastructure equipment, long-term training for publicsector staff, and designing and implementing evidence-based policies and strategies and monitor their progress and impacts. In the short term, a viable strategy to address the weak research-policy linkages would be the effective use of existing capacity. In the long term, with assistance from donors and international organizations, government should look into institutional arrangements for systematic linkages and sustainability of capacity-building efforts.

\section{Strengthening monitoring and evaluation systems}

Capacity building for designing and implementing M\&E systems will be an important step toward greater focus on results, accountability, and performance-based planning and decision-making among relevant organizations. Public-sector organizations should set a vision and strategic direction to design their M\&E frameworks and train staff in related skills such as data and statistical analysis and economic research to provide substantial, evidence-based strategic planning.

\section{From technical assistance to organizational strengthening}

Strengthening organizational capacity for public-sector organizations to perform more effectively will require technical assistance to design and manage financial and other systems, procedures, and resources. However, such technical assistance should focus on dual objectives of developing organizational procedures and the capacity for sustaining them.

\section{Systemic assessment of capacity constraints and strategic investments}

The design of capacity development investments need to adopt a dynamic and sustainable multi-stakeholder approach. This will need to include universities and colleges in the training programs and incorporate the training materials into their curriculum to ensure the continuity and institutionalization of training and learning efforts. The selection of individual trainees will have to be based on their ability to continue the training with other members of their organizations. A systematic assessment of the training landscape and the constraints and opportunities for the key actors and organizations is required before investing in capacity development.

\section{Empowering farmers' organizations}

There is a need to empower farmers' organizations to be strong voices and to advocate for the welfare of rural producers. Careful targeting of capacity-building efforts is 
critical to truly empower marginalized groups without promoting elite capture. The rural population will also need to improve their capacity to articulate their demands for rural services. Last, several incomplete elements in policy reforms such as clarity in fiscal allocations, definition of accountability measures, and civil-service reform need attention. The extent of public understanding and awareness is an indicator of the success of the reform process. Strategic communications are needed for informing the status of the reform process.

\section{Conclusion}

Achieving food security for all in developing countries requires appropriate institutional and policy reforms. However, the success of policy and institutional reforms is intricately linked to the capacity of the organizations and actors involved in these processes. Yet, applied studies on understanding the organizational and capacity constraints and challenges are few and far between. This is partly due to the single-disciplinary treatments of policy processes that remain the domain of political economists - mostly in developed countries - and the study of institutional, organizational, and capacity challenges by public administration and social scientists. Yet, understanding and solving institutional and policy systems challenges require multidisciplinary approach to the study of institutions that are context and time specific. Limited applications to developing country context is also due to lack of analytical and data collection methods to document the policy processes, institutional change, and organizational and individual capacities.

This paper brought the policy process and organization development disciplines to develop a conceptual framework to trace the levels, linkages, and influence of various organizations and actors in the policy process. It applied this framework to study the institutional and policy reforms that are currently underway in DRC, a country still slowly emerging from war and conflicts. Using an innovative methodology to map the policy process with a view to analyze the organizational and capacity challenges it identified various capacity and incentive bottlenecks in the agricultural sector.

Results indicated that moving the policy and institutional reform agenda forward will require higher level of political commitment, increased investment support, systematic capacity development at the organizational and individual levels, functioning monitoring and evaluation system, and improved research-policy linkages. A key lesson emerging from the case study is that while local ownership of the policy and institutional reform process has to be nurtured, allowing local policy makers to solve their problems in their own context is critical. Identifying opportunities for guiding the reform processes and providing strategic support to the existing local organizations by the external funders should begin from what is available within the country and by building upon them. The role of evidence-based analysis by developing the capacity of the local researchers in furthering institutional and policy reforms can hardly be overemphasized.

\section{Endnotes}

a Policy process is defined in this paper as the process of public policymaking where problems are conceptualized, discussed and debated, alternative solutions 
developed, policy choices are made, implemented, monitored, evaluated and revised (Sabatier 2007).

${ }^{\mathrm{b}}$ Capacity considered in this paper are human or individual (skills, knowledge, education, and training of individuals); organizational (physical and financial resources, and human resource and management systems in the organization); and institutional (work environment and culture, staff morale, motivations, and accountability within organization and across organizations).

${ }^{\mathrm{c}}$ Capacity gaps are defined in this paper as discrepancy between the expected or required capacity to achieve a set goal and actual or observed capacity.

${ }^{\mathrm{d}}$ MINRD was first created in the 1980s, but it was absorbed twice by MINAGRI and then re-created as an independent ministry.

${ }^{\mathrm{e}}$ Based on Decree Law 081 (July 2, 1998) on territorial and administrative organization of the Democratic Republic of Congo. This figure includes three districts in Kinshasa (with no chief of district). Most of the districts are to become provinces (except the newly created district of Plateaux), according to Article 2 of the Congolese Third Republic Constitution.

\section{Abbreviations}

BCC: Bangue Centrale du Congo [Central Bank of Congo]; BTC: Belgian Technical Cooperation; CAADP: Comprehensive Africa Agricultural Development Programme; CARGs: Agricultural and Rural Management Councils; COPEMECO: The Confederation of Small and Medium Enterprises of the Congo; DRC: Democratic Republic of Congo; FAO: Food and Agriculture Organization; FEC: Federation of Private Enterprises in Congo; FOLECO: Federation of Liac and Economics; GDP: Gross Domestic Product; IFPRI: International Food Policy Research Institute; INERA: National Institute for Agricultural Research and Studies (Institut National des Etudes et de la Recherche Agricole); MINAGRI: Ministry of Agriculture, Fisheries, and Livestock; MINRD: Ministry of Rural Development; MINREST: Ministry of Scientific and Technical Research; NGOs: Non-Governmental Organizations; NSSP: Nigeria Strategy Support Program; ODI: Overseas Development Institute; SADC: Southern African Development Community; UCC: Catholic University of Congo; UNIKIN: University of Kinshasa; USAID: United States Agency for International Development.

Competing interests

The authors declare that they have no competing interests.

\section{Authors' contributions}

CR, SCB and JU conducted the interviews and fieldwork together. CR conceptualized the framework and methods, analyzed the initial results and drafted the first version. SCB contributed on the literature review, framework and discussion sections. JU provided information and sections on the DRC context, made arrangements for the interviews to various officials and key informants in DRC, and added on the discussion and policy implications. All authors read and approved the final manuscript.

\section{Acknowledgements}

The authors would like to thank Cornelie Sifa Nduire and Joel K. Siku. The authors are very grateful for the invaluable guidance and comments from Regina Birner. Thanks go also to the DRC government officials and private individuals who shared data, information, and experiences, and the many representatives from various organizations whose active and dynamic participation in the interviews and focus groups gave rich resources and insights to this paper.

\footnotetext{
Author details

'Development Strategy and Governance Division, International Food Policy Research Institute (IFPRI), 2033 K Street, NW, Washington DC 20006, USA. ${ }^{2}$ Partnership, Impact and Capacity Strengthening Unit, International Food Policy Research Institute (IFPRI), 2033 K Street, NW, Washington DC 20006, USA. ${ }^{3}$ West and Central Africa Office, International Food Policy Research Institute (IFPRI), 2033 K Street, NW, Washington DC 20006, USA.
}

Received: 20 November 2013 Accepted: 7 April 2014

Published online: 24 June 2014

\section{References}

Aberman N, Schiffer E, Johnson M, Oboh V (2010) Mapping the Policy Process in Nigeria: Examining Linkages Between Research and Policy. International Food Policy Research Institute (IFPRI) Discussion Paper 01000. IFPRI, Washington, DC Adebayo K, Babu SC, Rhoe V (2009) Institutional Capacity for Designing and Implementing Agricultural and Rural Development Policies and Strategies in Nigeria. Nigeria Strategy Support Program (NSSP) Background Paper No. NSSP 008. IFPRI, Washington, DC

Ayuk ET, Marouani MA (2007) The Policy Paradox in Africa: Strengthening Links Between Economic Research and Policymaking. International Development Research Centre/Africa World Press, Ontario, Canada 
Babu SC (2013) Policy Process and Food Price Crisis: A Framework for Analysis and Lessons from Country Studies. Working Paper 2013/070. World Institute for Development Economics Research, Helsinki

Babu SC, Mensah R, Kolavalli S (2007) Does Training Strengthen Capacity? Lessons from Capacity Development in Ghana, Ministry of Food and Agriculture. Ghana Strategy Support Program (GSSP) Background Paper No. GSSP 0009. IFPRI, Accra, Ghana

BCC (Bangue Centrale du Congo [Central Bank of Congo]) $(2004,2005,2006,2007)$ Annual Report. BCC, Kinshasa

Booth D (2011) Aid, institutions and governance: what have we learned? Dev Policy Rev 29(S1):S5-S26

Cash DW, Clark W, Alcock F, Dickson NM, Eckley N, Guston DH, Jager J, Mitchell RB (2003) Knowledge systems for sustainable development. Proc Natl Acad Sci 100(14):8086-8091

Court J, Young J (2003) Bridging Research and Policy: Insights from 50 Case Studies. Overseas Development Institute (ODI) Working Paper 213. ODI, London

FAO (Food and Agriculture Organization of the United Nations) (2008) Evaluation of FAO Cooperation in Democratic Republic of Congo. Executive Summary, Kinshasa, FAO

Grindle MS (2007) Good enough governance revisited. Dev Policy Rev 25:533-574

Guston DH (2001) Boundary organizations in environmental policy and science: An introduction. Sci Technol Hum Values 26(4):399-408

IFPRI (International Food Policy Research Institute) (2012) Food Policy Capacity Indicators. Draft Report, IFPRI, Washington, DC

Killick T (2010) Development Economics in Action: A Study of Economic Policies in Ghana, 2nd edn. Routledge, London

Marshall J, McLean A (1988) Reflection in Action: Exploring Organizational Culture. In: Reason P (ed) Human Inquiry in Action. Sage Publications, London

Omamo S (2004) Bridging Research, Policy, and Practice in African Agriculture. Development Strategy and Governance Division Discussion Paper 10. IFPRI, Washington, DC

Resnick D, Birner R (2010) Agricultural strategy development in West Africa: The false promise of participation? Dev Policy Rev 28(1):97-115

Rivera W. Alex G (2004) Volume 2. Privatization of Extension Systems: Case Studies of International Initiatives, Agriculture and Rural Development. Discussion Paper 9. World Bank, Washington, DC

Ryan J (1999) Assessing the Impact of Rice Policy Changes in Vietnam and the Contribution of Policy Research. Impact Assessment Discussion Paper 8. IFPRI, Washington, DC

Sabatier PA (2007) Theories of the Policy Process, 2nd edn. Westview, Cambridge, MA

SADC (Southern African Development Community) (2009) SADC Regional Agricultural Policy (RAP)—National Review Report. Democratic Republic of Congo, Draft

Schiffer E (2007) The Power Mapping Tool: A Method for the Empirical Research of Power Relations. Discussion Paper 00703. IFPRI, Washington, DC

Stone D, Maxwell S, Keating M (2001) Bridging Research and Policy. Working Paper. Warwick University, Coventry, UK

Tollens E (2004) Les défis: Sécurité alimentaire et cultures de rente pour l'exportation - principales orientations et avantages comparatifs de l'agriculture en R.D. Congo, Table Ronde sur l'Agriculture en RDC, "Vers une stratégie de développement agricoles, base solide du décollage économique, Kinshasa", 19-20 Mars, 2004, Cercle de l'Alliance Belgo-Congolaise, 2004. Kinshasa: Cercle de l'Allinace Belgo-Congolaise, p 32

World Bank (1999) Capacity Building in the Agricultural Sector in Africa. World Bank Operations Evaluation Department, Spring 1999, No. 180, Washington, DC

World Bank (2006) Democratic Republic of the Congo: Agricultural Sector Review. Main Report, April 15. Report No. 30215-ZR. Washington, DC: World Bank.

World Bank (2010) Designing and Implementing Agricultural Innovation Funds: Lessons from Competitive Research and Matching Grant Projects. Washington, DC

Young J (2005) Research, policy, and practice: Why developing countries are different. J Int Dev 17:727-734

doi:10.1186/s40100-014-0004-3

Cite this article as: Ragasa et al:: Institutional reforms and agricultural policy process: lessons from Democratic Republic of Congo. Agricultural and Food Economics 2014 3:4

\section{Submit your manuscript to a SpringerOpen ${ }^{\circ}$} journal and benefit from:

- Convenient online submission

- Rigorous peer review

- Immediate publication on acceptance

- Open access: articles freely available online

- High visibility within the field

- Retaining the copyright to your article

Submit your next manuscript at $\gg$ springeropen.com 